\title{
Evaluation of Antimicrobial Efficacy of Ethanol Extracts of Fresh Citrus sinensis (Sweet Orange) Seeds against Selected Bacterial Strains
}

\author{
${ }^{* 1,2}$ OIKEH, EI; ${ }^{3}$ OVIASOGIE, FE; ${ }^{1}$ OMOREGIE, ES \\ ${ }^{*}$ Department of Biochemistry, Faculty of Life Sciences, University of Benin, PMB 1154, Benin City, Nigeria \\ ${ }^{2}$ Department of Chemistry, College of Arts and Sciences, University of Kentucky, Lexington, USA. \\ ${ }^{3}$ Department of Microbiology, Faculty of Life Sciences, University of Benin, PMB 1154, Benin City, Nigeria. \\ *Corresponding Author Email: ehigbai.oikeh@uniben.edu
}

\begin{abstract}
The antibacterial activities of fresh Citrus sinensis seed oil and non-oil extract are investigated in this study. Gram positive (Staphylococcus aureus and Enterococcus faecalis) and Gram negative (Pseudomonas aeruginosa, Escherichia coli and Salmonella spp.) bacterial strains are used in this study and antibacterial activity is estimated using the agar well diffusion method. Zones of inhibition were measured and the minimum inhibitory concentration and minimum bacteriostatic concentrations were determined. The results show that the non-oil extract had better antibacterial activities against Staphylococcus aureus, Enterococcus faecalis and Escherichia coli compared to the oil extract (zones of inhibition at $200 \mu \mathrm{g} / \mathrm{ml}$ of $12 \mathrm{~mm}, 8 \mathrm{~mm}$ and $2 \mathrm{~mm}$ respectively for the nonoil extract; $4 \mathrm{~mm}, 6 \mathrm{~mm}, 0 \mathrm{~mm}$ respectively for the seed oil). The seed oil however had better antibacterial activity compared to the non-oil extract in Salmonella spp. (zones of inhibition at $200 \mu \mathrm{g} / \mathrm{ml} \mathrm{of} 8 \mathrm{~mm}$ for the seed oil compared to $4 \mathrm{~mm}$ for the non-oil extract). Pseudomonas aeruginosa showed similar susceptibility to both extracts at both concentrations studied (zones of inhibition of $4 \mathrm{~mm}$ and $2 \mathrm{~mm}$ for both extracts at $200 \mu \mathrm{g} / \mathrm{ml}$ and 100200 $\mu \mathrm{g} / \mathrm{ml}$ respectively). Minimum inhibitory concentrations ranged from $50-100 \mu \mathrm{g} / \mathrm{ml}$ while minimum bacteriostatic concentrations ranged from $100-200 \mu \mathrm{g} / \mathrm{ml}$. We conclude from our findings that both extracts hold promise in the development of antimicrobial therapeutics.
\end{abstract}

\section{DOI: https://dx.doi.org/10.4314/jasem.v24i2.9}

Copyright: Copyright $(\subset 2020$ Oikeh et al. This is an open access article distributed under the Creative Commons Attribution License (CCL), which permits unrestricted use, distribution, and reproduction in any medium, provided the original work is properly cited.

Dates: Received: 16 November 2019; Revised: 11 January 2020; Accepted: 22 February 2020

Keywords: Citrus sinensis, Antibacterial, minimum inhibitory concentration, minimum bacteriostatic concentration

Medicinal plants have for thousands of years been used in the management of microbial infections. Plants are natural sources for antimicrobial compounds as they naturally produce a range of antimicrobial compounds to ward off microbial organisms competing with them in their environment (Dhiman et al., 2012; Thawabteh et al., 2019). Several new antibiotics have been produced by pharmacological companies in the past few decades. However, microorganisms have continued to exploit their genetic ability to acquire resistance to therapeutic drugs targeted against them. The high costs and side effects of popular synthetic antibiotics are also topical issues that bother clinicians and drug researchers. This has therefore led scientists to continually screen for and discover newer and potentially better antibiotics from medicinal plants (Tumane et al., 2014; Rajeswari, 2015; Baym et al., 2016; Thawabteh et al., 2019). Random screening of natural plants parts for pharmacologically active compounds has proven to be especially useful in the discovery of antibiotics. Isolation, characterization and chemical synthesis of identified lead compounds and analogues has proven to be useful globally (Mahesh and Satish, 2008).

Citrus sinensis belongs to the Rutaceae family. It is native to China but is widely cultivated throughout the world. It is currently the most cultivated and commercialized specie of citrus (Tumane et al., 2014; Yekeen et al., 2014; Favela-Hernández et al., 2016). Fresh citrus fruits are consumed on a large scale and large quantities are processed into juice. Citrus fruit wastes, generated after consumption of the juice include the peels, albedo and seeds. These wastes are a potential source of valuable by products (Oikeh et al., 2013; Yekeen et al., 2014). Citrus peels have been demonstrated to possess several phytochemicals such as phenolics, flavonoids and glycosides. Several studies have reported the antioxidant and antimicrobial effects of citrus juices while citrus peel extracts have also been found to possess good antioxidative potential (Oikeh et al., 2014; Tumane et al., 2014). 
Research into Citrus sinensis wastes have focused majorly on the peels and oil extracted from the seed. The non-oil solid residue derived from oil extraction from the seeds is usually not given paid attention to. This study compares the antibacterial activities of oil extracted from Citrus sinensis seed as well as the nonoil seed extract. The results in this paper draw more attention to the non-oil extract from the seed as a potential source of bioactive materials with antimicrobial importance.

\section{MATERIALS AND METHODS}

Raw materials: Fresh oranges were purchased from New Benin Market in Benin City, Nigeria. The fruits were washed with distilled water and the peels removed with the aid of a sharp knife. A juice extractor was used to extract the juice and the seeds collected. The seeds were pulverized immediately after collection.

Preparation of plant extract: The pulverized samples were subjected to Soxhlet extraction for a period of 12 hours with $500 \mathrm{ml}$ of ethanol under room temperature and concentrated using rotary evaporator at low pressure. The top oil layer was separated from the lower solid extract by carefully pouring. The oil and non-oil extract were stored in the refrigerator till required for use.

Test microorganisms: Five bacterial strains were used in this study. Two were Gram positive (Staphylococcus aureus and Enterococcus faecalis) while the other three were Gram negative (Pseudomonas aeruginosa, Escherichia coli and Salmonella spp). All microorganisms were obtained from Lahor Research and Diagnostic Laboratories, Benin City, Nigeria.

Antimicrobial Susceptibility assay: Test organisms were sub-cultured onto fresh suitable broth medium. Broth cultures were then incubated at $37^{\circ} \mathrm{C}$ till the turbidity of $0.5 \mathrm{McF}$ arland's standard was obtained. Mueller-Hinton agar was used as bacterial medium. The turbidity of the actively growing broth culture was then adjusted with sterile saline to obtain 0.5 McFarland's standard turbidity $\left(10^{8} \mathrm{CFU} / \mathrm{ml}\right)$. This was then used to flood the surface of solid MuellerHinton agar plates and then drained dry. Wells of 5 $\mathrm{mm}$ in diameter and about $2 \mathrm{~cm}$ apart were punched in the culture media with sterile cork borer. The extracts were then used to fill the boreholes. Each plate was kept in the refrigerator at $4{ }^{\circ} \mathrm{C}$ for $1 \mathrm{hr}$ before incubating at $37{ }^{\circ} \mathrm{C}$ for $24 \mathrm{hr}$. Zones of inhibition around the wells, measured in millimetres, were used as positive bioactivity.
Minimum inhibitory concentration (MIC): The organisms that showed susceptibility to the different solvent extracts were then introduced into the broths containing different concentrations of each extract (Serial dilutions of the extracts corresponding to 200 $\mu \mathrm{g} / \mathrm{ml}, 100 \mu \mathrm{g} / \mathrm{ml}, 50 \mu \mathrm{g} / \mathrm{ml}, 25 \mu \mathrm{g} / \mathrm{ml}$ and 12.5 $\mu \mathrm{g} / \mathrm{ml})$. The tubes were then incubated for 24 hours at $37^{\circ} \mathrm{C}$. The MIC was taken as the lowest concentration of the extracts that did not permit any visible growth.

Minimum bactericidal concentration $(M B C)$ : The tubes that showed no turbidity in the MIC test were taken and a loop-full from each tube was streaked on Mueller Hinton agar. The plates were incubated for 24 hours at $37^{\circ} \mathrm{C}$ and the absence of growth was observed. The concentration of the extracts that showed no growth was recorded as the MBC.

\section{RESULTS AND DISCUSSION}

The data of plants containing bioactive components is by no means a complete one as several plant species with medicinal value are still yet to be discovered. Thus, screening of plants for a wide array of medicinal properties is an ongoing process. Several plants and plant parts hold promise as rich reservoirs of antimicrobial compounds and thus require sustained pharmacological investigations (Pandey et al., 2011). We have earlier on shown that Citrus sinensis seeds contain phytoconstituents such as alkaloids, flavonoids, tannins, saponins, cardiac glycosides and steroids (Oikeh et al., 2013). Several of these phytoconstituents are known to contain a wide spectrum of antimicrobial properties (Owoseni and Ajayi, 2010; Dhiman et al., 2012).

The agar disc diffusion method was used in vitro to assay for the antibacterial activity of the Citrus sinensis seed oil and extract against five (5) bacterial strains. Tables 1 and 2 show the bacterial growth inhibition of both extracts against the selected bacterial strains. The results show that both $C$. sinensis seed and oil extracts possess varying degrees of antibacterial activities against Staphylococcus aureus, Enterococcus faecalis, Pseudomonas aeruginosa, and Salmonella spp. Escherichia coli was however not susceptible to the $C$. sinensis seed oil as no inhibition of growth was observed. Minimum inhibitory concentration was lowest in the $C$. sinensis seed oil against Pseudomonas aeruginosa and Salmonella spp (50 $\mu \mathrm{g} / \mathrm{ml}$ ) with an MBC of100 $\mu \mathrm{g} / \mathrm{ml}$ for these organisms (Table 3). An MIC value of $100 \mu \mathrm{g} / \mathrm{ml}$ was observed for the seed extract against all the bacterial strains tested. Maximum antibacterial activity for the seed extract was observed against Staphylococcus aureus with a $12 \mathrm{~mm}$ zone of inhibition while the seed oil had Maximum antibacterial activity against 
Salmonella spp (8 $\mathrm{mm}$ zone of inhibition). Measurement of zones of inhibition against Grampositive and Gram-negative bacteria strains show that the seed extract had larger zones of inhibition than the seed oil against both Gram-positive organisms (Staphylococcus aureus and Enterococcus faecalis) at the concentrations studied.

Table 1: Zones of inhibition ( $\mathrm{mm}$ ) of some Gram positive bacterial strains at various concentrations of extracts of fresh Citrus sinensis seed.

\begin{tabular}{lllll}
\hline \multirow{2}{*}{$\begin{array}{l}\text { Concentration } \\
(\mu \mathrm{g} / \mathrm{ml})\end{array}$} & \multicolumn{2}{l}{ Staphylococcus aureus } & \multicolumn{2}{l}{ Enterococcus faecalis } \\
\cline { 2 - 5 } & Seed Extract & Seed Oil & Seed Extract & Seed Oil \\
\hline 200 & 12 & 4 & 8 & 6 \\
100 & 8 & 2 & 4 & 3 \\
50 & - & - & - & - \\
\hline
\end{tabular}

Table 2: Zones of inhibition ( $\mathrm{mm}$ ) of some Gram negative bacterial strains at various concentrations of extract of fresh Citrus sinensis seed.

\begin{tabular}{lllllll}
\hline \multirow{2}{*}{$\begin{array}{l}\text { Concentration } \\
\mu \mathrm{g} / \mathrm{ml})\end{array}$} & \multicolumn{2}{l}{ Escherichia coli } & \multicolumn{2}{l}{ Salmonella spp. } & \multicolumn{2}{c}{ Pseudomonas aeruginosa } \\
\cline { 2 - 7 } & Seed Extract & Seed Oil & Seed Extract & Seed Oil & Seed Extract & Seed Oil \\
\hline 200 & 2 & - & 4 & 8 & 4 & 4 \\
100 & 1 & - & 2 & 6 & 2 & 2 \\
50 & - & - & - & 4 & - & 1 \\
\hline
\end{tabular}

Table 3: Minimum inhibitory and bacteriostatic concentrations $(\mu \mathrm{g} / \mathrm{ml})$ of $C$. sinensis seed extracts against microbial strains.

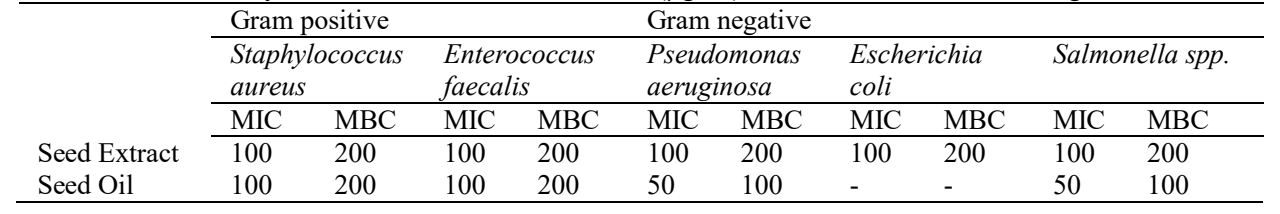

The Citrus sinensis seed oil did not show any antibacterial activity against Escherichia coli as demonstrated by the lack of any visible zone of inhibition. This is in contrast to the seed extract with 1 and $2 \mathrm{~mm}$ zones of inhibition at 100 and $200 \mu \mathrm{g} / \mathrm{ml}$ of the extract respectively. These observed zones of inhibition are however not high enough to conclude that the seed extract may be a good source of antimicrobial agents against $E$. coli.

The antimicrobial activities of the Citrus sinensis seed oil and extract observed in this study against different bacterial strains suggests that these extracts may be starting materials for the development of broadspectrum antimicrobial agents. Variations in the degree of antimicrobial activity of both extracts suggest that both extracts may have diverse bioactive compounds responsible for their antibacterial activities.

Differences in the antimicrobial activities observed may also be attributed to the differences in the nature of both samples. The hydrophobic nature of the oil may have prevented the uniform diffusion of the oil through the agar medium (Hammer et al., 1999). Bearing this in mind, the better antibacterial activity of the oil observed against Salmonella spp. suggests that the oil may be a reservoir of potent antibacterial agent against this bacteria.

Conclusion: We conclude from our findings that oils extracted from oil-rich plant materials may not be responsible for all the health benefits ascribed to the plant. This study has provided preliminary in vitro data on the antibacterial potential of Citrus sinensis seed oil and non-oil extract. Taking into cognizance the wide differences existing in published works as per the antibacterial activities of plant materials in vitro; the authors recommend further in vitro and in vivo studies for the possible identification of compound(s) responsible for the bioactivities.

\section{REFERENCES}

Baym, M; Stone, LK; Kishony, R (2016). Multidrug evolutionary strategies to reverse antibiotic resistance. Science. 351(6268):aad3292.

Dhiman, A; Nanda, A; Ahmad, S; Narasimhan, B (2012). In vitro antimicrobial status of methanolic extract of Citrus sinensis Linn. fruit peel. Chron. Young Sci. 3(3): 204 -208.

Favela-Hernández， JMJ; González-Santiago， O; Ramírez-Cabrera, MA; Esquivel-Ferriño, PC; Camacho-Corona, MDR (2016). Chemistry and Pharmacology of Citrus sinensis. Molecules. 21(2):247.

Hammer, KA; Carson, CF; Riley, TV (1999). Antimicrobial activity of essential oils and other plant extracts. J. Appl. Microbiol. 86:985-990. 
Mahesh, B; Satish, S (2008). Antimicrobial activity of some important medicinal plant against plant and human pathogens. World J. Agric. Sci. 4 (S): 839843.

Oikeh, EI; Oriakhi, K; Omoregie, ES (2013). Proximate Analysis and Phytochemical Screening of Citrus sinensis Fruit Wastes. Bioscientist. 1(2): 164 - 170 .

Oikeh, EI; Oriakhi, K; Omoregie, ES. (2014). Phenolic Content and in vitro Antioxidant Activities of Sweet Orange (Citrus sinensis L.) Fruit Wastes. Arc. Bas. Appl. Med. 2(2): $119-$ 126.

Owoseni, AA; Ajayi, A (2010). Antimicrobial properties of ethanolic and aqueous extracts of Cymbopogon citratus on selected bacteria and fungi. J. Med. Appl. Biosci. 2: 64-73.

Pandey, A; Kaushik, A; Tiwari, SK (2011). Evaluation of antimicrobial activity and phytochemical analysis of Citrus limon. J. Pharm. Biomed. Sci. 13(13): 17.
Thawabteh, A; Juma, S; Bader, M; Karaman, D; Scrano, L; Bufo, SA; Karaman, R (2019). The Biological Activity of Natural Alkaloids against Herbivores, Cancerous Cells and Pathogens. Toxins. 11 (11), 656.

Tumane, PM; Meshram, VG; Wasnik, DD (2014). Comparative study of antibacterial activity of peel extracts of Citrus aurantium L. (bitter orange) and Citrus medica L. (lemon) against clinical isolates from wound infection. Intl. J. Pharma Bio Sci. 5(1): $382-387$.

Yekeen, MO; Ajala, OO; Alarape, AB (2014). Antifungal activities of Citrus sinensis seed oil against Lentinus sajor-caju. Adv. Appl. Sci. Res. 5(3):109-113.

Rajeswari, A (2015). Evaluation of phytochemical constituents, quantitative analysis and antimicrobial efficacy of potential herbs against selected microbes. Asian J. Pharm. Clin. Res. 8(2): 232-237. 